\title{
Drug Release Formulation
}

National Cancer Institute

\section{Source}

National Cancer Institute. Drug Release Formulation. NCI Thesaurus. Code C42705.

A category based upon the characteristics of release of active and/or inert ingredient(s). 